\title{
Le Politique et le Féminin. Les femmes de pouvoir dans les Mémoires d'Ancien Régime, dir. C. FRANCÈS
}

\section{Debora Sicco}

\section{(2) OpenEdition}

\section{Journals}

\section{Edizione digitale}

URL: https://journals.openedition.org/studifrancesi/43893

DOI: 10.4000/studifrancesi.43893

ISSN: 2427-5856

\section{Editore}

Rosenberg \& Sellier

\section{Edizione cartacea}

Data di pubblicazione: 1 juin 2021

Paginazione: 217

ISSN: 0039-2944

\section{Notizia bibliografica digitale}

Debora Sicco, «Le Politique et le Féminin. Les femmes de pouvoir dans les Mémoires d'Ancien Régime, dir. C. FrancĖs», Studi Francesi [Online], 193 (LXV | I) | 2021, online dal 01 juillet 2021, consultato il 15 octobre 2022. URL: http://journals.openedition.org/studifrancesi/43893 ; DOI: https://doi.org/10.4000/ studifrancesi.43893

Questo documento è stato generato automaticamente il 15 octobre 2022

\section{(c) $($ ) $(9)$}

Creative Commons - Attribuzione - Non commerciale - Non opere derivate 4.0 Internazionale - CC BYNC-ND 4.0

https://creativecommons.org/licenses/by-nc-nd/4.0/ 


\title{
Le Politique et le Féminin. Les femmes de pouvoir dans les Mémoires d'Ancien Régime, dir. C. FRANCÈS
}

\author{
Debora Sicco
}

\section{NOTIZIA}

Le Politique et le Féminin. Les femmes de pouvoir dans les Mémoires d'Ancien Régime, dir. C. FRANCÈs, Paris, Classiques Garnier, 2020, 319 pp.

1 In che modo le donne dell'Ancien Régime hanno preso parte alla vita politica del tempo, dalla quale erano giuridicamente escluse? $\mathrm{E}$ in che modo questa azione politica è stata narrata dalle sue protagoniste o da coloro che hanno assistito al loro operato? Fra gli scritti che si soffermano sul potere femminile e sulla sua rappresentazione, i mémoires offrono testimonianze e spunti di riflessione particolarmente significativi. Il presente volume, così come il convegno che ne è stato all'origine, si concentra proprio su questo genere letterario, nel tentativo di far emergere «la spécificité des Mémoires parmi l'ensemble des écrits qui ont contribué à configurer la place du féminin à l'intérieur du pouvoir, à en façonner les images et à développer une intelligence de son action» (Introduction, p. 7). Grazie a questa prospettiva, esso arricchisce di un importante tassello la storia delle donne, che negli ultimi decenni si è affermata con sempre maggior successo.

2 Nel corso dell'Ancien Régime il rapporto tra femminilità e potere è assai conflittuale: ufficialmente escluse dalla sfera pubblica, le donne hanno costantemente agito ai suoi margini, riuscendo talvolta ad accedere al potere come eredi o rappresentanti di una figura maschile. È questo il caso di Jeanne d'Albret e di Marguerite de Valois, su cui si sofferma Nadine KUPERTY-TSUR (La représentation du pouvoir politique dans les Mémoires de Jeanne d'Albret et de Marguerite de Valois, pp. 21-38), ma anche di Cristina di Svezia, Anna d'Austria e Caterina II. La prima parte del volume, «Au cœur du pouvoir. Figures de 
souveraines» è dedicata proprio al modo in cui queste donne sono ascese al potere e hanno cercato di legittimarlo. Effettivamente, esse erano pienamente consapevoli della problematicità del proprio status: le donne che si trovano a occupare posizioni di potere, diversamente dagli uomini, evocano spesso il proprio genere come un ostacolo o sentono l'esigenza di giustificare la propria posizione agli occhi degli altri, forse persino ai propri occhi.

Un'altra questione cruciale è quella della «Frontière du pouvoir féminin. Entre public et privé», oggetto della seconda parte del volume. A questo proposito, la Fronda, caratterizzata da un'intensa partecipazione femminile, costituisce un punto di svolta: «L'échec de la Fronde signe tout à la fois l'échec des mouvements de résistance nobiliaire à la montée de l'absolutisme, et l'échec de l'engagement féminin dans l'espace politique» (Sandrine CAROFF-URFER, Les femmes dans les Mémoires du cardinal de Retz. Le mauvais genre de la politique?, p. 113). Successivamente, le donne - nobili o meno che siano - sono relegate nella sfera privata e, se esercitano il potere, lo fanno nell'ombra e in maniera indiretta, come ribadisce Delphine Mousquin nel suo saggio (Dans l'ombre et l'obscurité ou comment le pouvoir vient aux femmes dans les Mémoires de Saint-Simon, pp. 143-155).

4 Esistono, in ogni caso, figure femminili forti, come quelle che negli scritti autobiografici di Madame Dunoyer sono presentate in opposizione a figure maschili deboli: le donne possiedono talvolta la forza morale di sfidare il potere, talaltra la forza più subdola che consente di conquistarlo giocando con la seduzione. Un altro interessante risvolto del potere femminile, che emerge nella terza e ultima parte del volume - «Face au pouvoir. Luttes, écarts et marginalités» - è il potere del ragionamento, rafforzato e praticato attraverso la scrittura, come nel caso di Madame de Genlis (Josiane GUITARD-MOREL, Félicité de Genlis, gouverneur des enfants d'Orléans, femme de pouvoir, pp. 233-249). Ma neanche questo potere è facilmente accessibile; infatti, la scelta di una donna di affermarsi come autrice è percepita come pericolosa, in particolare quando, anziché limitarsi ai generi del romanzo e delle memorie, si avventura sul terreno della storia.

La ricezione delle Considérations sur les principaux événements de la Révolution française di Germaine de Staël ne è un'emblematica testimonianza (Laetitia SAINTES, Polémique et bataille du genre. La réception des Considérations sur la Révolution française de Germaine de Staël, pp. 251-274): secondo radicati stereotipi di genere, le donne - costituzionalmente dominate dalla propria immaginazione e dai propri sentimenti - sarebbero incapaci della lucidità e dell'obiettività che la storia richiede. La storiografia ufficiale è dunque maschile, anche se come mostra Éliane VIENNOT nell'epilogo del volume (Le recours à l'histoire des femmes illustres aux lendemains de la chute de l'Ancien Régime. 1789-1860, pp. 275-288), gli esempi del potere femminile hanno continuato a essere tramandati. Semplicemente, sia durante l'Ancien Régime sia subito dopo la sua caduta, la società non era ancora pronta a riconoscere alle donne il diritto di scrivere la storia e, soprattutto, quello di farla. 